\title{
Preparation of superhydrophobic and transparent micro-nano hybrid coatings from polymethylhydroxysiloxane and silica ormosil aerogels
}

\author{
Saravanan Nagappan ${ }^{\dagger}$, Jin Joo Park ${ }^{\dagger}$, Sung Soo Park and Chang-Sik Ha ${ }^{*}$
}

\begin{abstract}
Superhydrophobic and transparent polymethylhydroxysiloxane (PMHOS)/silica ormosil aerogel hybrids were prepared successfully by mixing of PMHOS with various weight percentages of silica ormosil aerogels (as synthesized from methyltriethoxysilane (MTES) and methyltrimethoxysilane (MTMS) precursors) in separate seal perfume glass vials. The hybrids were spin coated on glass substrate at $1000 \mathrm{rpm}$ for 60 seconds and used for further analysis. The surface morphology and chemical compositions of the hybrids were analyzed by high resolution scanning electron microscopy, high resolution transmission electron microscopy, atomic force spectroscopy, adsorption and desorption isotherm, and X-ray photoelectron spectroscopy. The transparency, thermal decomposition and static contact angle (SCA) of each sample were measured by UV-Visible spectrophotometer, TGA and drop shape analysis system, respectively. The spin coated substrates showed good superhydrophobic properties, thermal stability as well as transparency on the glass substrates.
\end{abstract}

Keywords: Superhydrophobic; Transparent; Polymethylhydroxysiloxane; Silica ormosils; Micro-nano hybrid

\section{Background}

Transparency of a substrate is an important factor for coating applications. Transparent substrates with several surface properties such as superhydrophilic (contact angle, $\left.\mathrm{CA}, \leq 5^{\circ}\right)$, hydrophilic $\left(\mathrm{CA},<90^{\circ}\right)$, hydrophobic $\left(\mathrm{CA} \geq 90^{\circ}\right)$ and superhydrophobic $\left(\mathrm{CA} \geq 150^{\circ}\right)$ surfaces were prepared using various organic and inorganic hybrid materials [1-5]. These types of substrates were used widely in a range of applications such as anti-stain coating, anti-fogging, solar cell, flexible substrate fabrication, self-cleaning, and anti-icing coatings [6-11]. The coating methods such as dip coating, spin coating, spraying, and casting methods were used for the preparation of transparent substrates [12-15]. Nakajima et al. prepared transparent superhydrophobic surface by spin coating method under the sublimation of aluminum acetylacetonate (AACA) followed by fluorosilane treatment

\footnotetext{
*Correspondence: csha@pnu.edu

${ }^{\dagger}$ Equal contributors

Department of Polymer Science and Engineering, Pusan National University, Busan 609-735, Republic of Korea
}

[16]. In another method, the authors also fabricated similar type of transparent superhydrophobic surface using AACA and titanium acetylacetonate (TACA) and fluorosilane [17]. The obtained superhydrophobic surface showed almost $100 \%$ transparency when the concentration of $\mathrm{TiO}_{2}$ was lower than 20\%. Meanwhile, increasing the concentration of $\mathrm{TiO}_{2}$ would lead to reduce the transparency of the coated substrate. Xu et al. recently prepared highly transparent superhydrophobic substrates by spin coating of fluorinated silica nanoparticles on silica wafer or other substrates [18]. The spin coated substrates can produce over $95 \%$ of transparency with superhydrophobicity. Fluorine based silane precursors of low surface energy were used widely for changing the hydrophobic surface to superhydrophobic surface $[19,20]$. This is due to the formation of thin layers of hydrophobic low surface energy materials on the pretreated hierarchical substrates. On the other hand, this might depend on the concentration of low surface energy material used for surface modification. Increasing the concentrations of fluoro silane to other precursor 
would enhance the surface properties. In another case, long chain alkyl or aromatic compounds were also used for surface treating of hydrophobic surfaces to produce superhydrophobic surface [21,22].

Recently we developed novel bio-inspired superhydrophobic hybrid micro-nanocomposites with mesoporous, highly stable to various drying temperatures, non-stick and self-cleaning properties on any substrate [23-25]. We used lotus leaf (LL) powder, polymethylhydroxysiloxane (PMHOS), and phenyl substituted silica ormosils (PSiOr) for the preparation of superhydrophobic hybrid micronanocomposites in ethanol $/$ methanol $/ \mathrm{H}_{2} \mathrm{O}$. Meanwhile, the hybrid micro-nanocomposites suspension showed transparency lower than $70 \%$ on a glass substrate by drop or spin coating method [26]. This is due to the presence of LL powder. Superhydrophobic PMHOS powder was synthesized from polymethylhydrosiloxane (PMHS) based on the reported procedure elsewhere [23]. PMHS is a low molecular weight siloxane based material, which is used widely in many applications such as fabrication of superhydrophobic surface and materials, catalysis, transparent surface fabrications, actuators, and etc. [6,7,27-29]. This is due to ease of availability and non-toxic properties of PMHS. The introduction of functional silica ormosil aerogel to the superhydrophobic powder would enhance the surface property of the material by the formation hierarchical particles in the suspension [23].

In this work, we discussed the fabrication of transparent, and almost complete superhydrophobic surfaces by the introduction of methyltriethoxysilane (MTES) or methyltrimethoxysilane (MTMS) to the PMHOS using metha$\mathrm{nol} / \mathrm{H}_{2} \mathrm{O}$. The suspension that was prepared by mixing PMHOS and silica ormosil aerogel obtained from MTES or MTMS in the absence of LL powder in methanol/ $\mathrm{H}_{2} \mathrm{O}$ showed enhanced transparency on the coated substrate than the substrate prepared in the presence of LL powder as well as in methanol/ethanol/ $\mathrm{H}_{2} \mathrm{O}$ solvents [26].

\section{Methods}

\subsection{Materials}

Poly(methylhydrosiloxane) (PMHS, Mn 1700 to 3200), methyltriethoxysilane (MTES, 99\%), methyltrimethoxysilane (MTMS, $98 \%$ ), oxalic acid $(\geq 99 \%)$ and ammonium hydroxide solution (ACS reagent, 28 to $30 \% \mathrm{NH}_{3}$ basis) were acquired from Sigma-Aldrich. Sodium hydroxide $(\mathrm{NaOH})$ was supplied from Junsei Chemical Co. Ltd. Anhydrous methanol (special grade) was purchased by Carlo Erba reagents Co. Ltd. Double deionized water (surface tension, $72.8 \mathrm{mN} / \mathrm{m}$ ) was used in all experiments.

\subsection{Synthesis of methyl substituted silica ormosil (MeSiOr) aerogel}

1 mL MTES was added into various volume of methanol

$(4.17 \mathrm{~mL}, 7.0 \mathrm{~mL}$ and $9.74 \mathrm{~mL}$ ) in different seal perfume glass vials $(100 \mathrm{~mL})$ followed by the addition of oxalic acid $(0.5 \mathrm{~mL}$ of $0.001 \mathrm{M})$ solution. The solution was hydrolyzed by stirring for $30 \mathrm{~min}$ followed by stored at room temperature for $24 \mathrm{~h}$. Ammonium hydroxide $\left(0.61 \mathrm{~mL}\right.$ of $11.2 \mathrm{M}$ (28 to $30 \%$ of $\left.\mathrm{NH}_{3}\right)$ ) solution was added dropwise to the solution, stirred for $15 \mathrm{~min}$ and stored to produce gelated silica ormosil aerogel by storing at room temperature for 2 days. The gel was redispersed in $10 \mathrm{~mL}$ methanol and ultrasonicated for $5 \mathrm{~min}$ $[11,23]$. The obtained silica ormosil aerogel samples were called MeSiOr EX, MeSiOr EY and MeSiOr EZ, respectively, according to the volume of methanol to MTES. Similar experiment was also carried out with constant volume of MTMS, which were named MeSiOr MX, MY, and MZ, respectively. The detailed synthesis of the materials was shown in Scheme 1.

\subsection{Preparation of superhydrophobic hybrid suspension}

In a $30 \mathrm{~mL}$ glass vial $0.1 \mathrm{~g}$ PMHOS, $8 \mathrm{~g}$ methanol and $1 \mathrm{~g}$ deionized water were placed and stirred well for $1 \mathrm{~h}$ followed by the addition of various weight percentages of MeSiOr EZ suspension to the PMHOS suspension, and stirred further at room temperature for $24 \mathrm{~h}$. The obtained hybrid suspensions were called PEZA, PEZB, PEZC, PEZD and PEZE. (Scheme 1 and Table 1), whereas $\mathrm{P}, \mathrm{EZ}$ and (A-E) means the presence of PMHOS, MeSiOr EZ and various weight percentages of $\mathrm{MeSiOr}$ EZ in PMHOS. The suspensions were ultrasonicated for 2 mins and spin coated at $1000 \mathrm{rpm}$ on a precleaned glass substrate and cured at room temperature. Similar experiments were also carried out with various weight percentages of MeSiOr MZ, which were called PMZA, PMZB, PMZC, PMZD and PMZE, whereas P, $M Z$ and (A-E) means the presence of PMHOS, MeSiOr $\mathrm{MZ}$ and various weight percentages of MeSiOr MZ in PMHOS.

\subsection{Characterization}

High-resolution scanning electron microscopy (HRSEM, Hitachi S-4800) and high-resolution transmission electron microscopy (HRTEM, JEM 2011 at $200 \mathrm{kV}$ ) were used to analyze the micro-nano surface morphology. Prior to the HRSEM measurement, the samples were coated with osmium tetraoxide (Hatfield, PA-19440), whereas, prior to the HRTEM measurement, the sample was dispersed well in ethanol and collected on a copper grid. The surface roughness of the spin coated substrates were predicted by atomic force microscopy (AFM) in tapping mode (Digital instruments nanoscope IIIa (USA) - Veeco metrology group) at a scanning rate of $1.49 \mathrm{~Hz}$ and on $5 \mu \mathrm{m}$ data scales. The chemical compositions present in the samples were measured by X-ray photoelectron spectroscopy (XPS, Thermo VG Scientific (U.K), Multi Lab) using the $\mathrm{Al} \mathrm{K \alpha}(\mathrm{h} v=1486.6 \mathrm{eV})$ and $\mathrm{Mg} \mathrm{K \alpha}(\mathrm{h} v=(\mathrm{h} v=1253.6 \mathrm{eV})$ 




Table 1 Preparation of PMHOS/silica ormosil aerogel hybrids of various ratios

\begin{tabular}{lllll}
\hline $\begin{array}{l}\text { Sample } \\
\text { name }\end{array}$ & PMHOS (g) & Methanol (g) & Water (g) & $\begin{array}{l}\text { Silica } \\
\text { ormosil aerogel } \\
\text { suspension }(\mathbf{g})\end{array}$ \\
\hline PEZA, PMZA & 0.1 & 8 & 1 & 0 \\
PEZB, PMZB & 0.1 & 8 & 1 & 0.02 \\
PEZC, PMZC & 0.1 & 8 & 1 & 0.05 \\
PEZD, PMZD & 0.1 & 8 & 1 & 0.08 \\
PEZE, PMZE & 0.1 & 8 & 1 & 0.1 \\
\hline
\end{tabular}

Note: P-PMHOS; EZ-MeSiOr EZ; MZ-MeSiOr MZ; (A-E)-various weight percentage of $E Z$ or $M Z$ based on PMHOS. line in the binding energy analysis range of $0-600 \mathrm{eV}$ in constant analyzer energy mode. The surface areas, pore volumes and pore diameters of the samples were obtained from Micromeritics ASAP 2020 V3.04 G, and calculated using the Brunauer-Emmett-Teller (BET) and BarrettJoyner-Halenda (BJH) analysis. Thermogravimetric analysis (TGA, Q50 V6.2, Build 187, TA instruments, U.S) was performed in a nitrogen atmosphere at a heating rate at $10^{\circ} \mathrm{C} / \mathrm{min}$. The transparency of the coated substrates were measured by UV-Visible spectrophotometer (Hitachi U-2010) in the spectral wavelength range of 400-800 nm, under the conditions of $200 \mathrm{~nm} / \mathrm{min}$ scanning speed, $1 \mathrm{~nm}$ sampling interval, and $2 \mathrm{~nm}$ slit width. The surface wettability was measured by drop shape analysis system (DSA 100, Krüss GmbH, Germany) at room temperature (500- $\mu \mathrm{L}$ syringe, needle diameter and length $(0.5 \mathrm{~mm}$ and $38 \mathrm{~mm})$ ). 


\section{Results and discussion}

The surface morphologies of the silica ormosil aerogel and siloxane hybrids are shown in Figure 1. The methyl functionalized silica ormosil aerogel showed densely packed silica nanoparticles on the spin coated substrate. This is due to the aggregation of silica ormosil aerogel networks at lower volume $(4.2 \mathrm{~mL})$ of methanol to MTES (Figure 1a). Meanwhile, porous structure was formed by increasing the volume of methanol to $7.0 \mathrm{~mL}$ and $9.74 \mathrm{~mL}$ (Figure $1 \mathrm{~b}$ and $\mathrm{c}$ ). Although the gels were redispersed with similar volume percentages of methanol $(10 \mathrm{~mL})$, the porous structure was mainly due to the gelation effect. The gels were dispersed well at higher volume percentages of methanol and reduced the surface aggregation, which creates the porous structure on the surface. The spin coated substrate also showed porous structure, which was increased by increasing the dispersibility of the silica ormosil aerogel. Similar results were also obtained for the silica ormosil aerogel obtained by MTMS (Figure 1d) [11]. Figure 1d clearly showed the formation of hierarchical surface morphology as compared with the silica ormosil aerogel surfaces obtained in the presence of MTES (Figure 1a-c). PMHOS is highly hydrolyzed and condensed solid siloxane polymer. PMHOS has hydroxyl and methyl functional groups on the surface, which makes the surface aggregation of micro-nanoparticles to form hierarchical surface. The addition of MeSiOr EZ or MeSiOr MZ suspension to the PMHOS suspension resulted in the formation of more aggregated morphology. The enhanced aggregation was mainly due to the hydroxylation and condensation of hydrophobic methyl and hydrophilic hydroxyl groups in the siloxane and silica ormosil aerogel. HRTEM images of
PEZE clearly illustrate the porous and hierarchical morphology of the material (Figure 2). The spin coated substrate showed higher roughness due to the enhancement of surface aggregation. This could be confirmed further by AFM images (Figure 3). Surface roughness (Ra) and root mean square roughness (RMS) are almost similar property for the fabrication of superhydrophobic surface, though the surface property mainly depends on the Ra value than the RMS value of the coated surface. Rough surfaces sometime can show hydrophobic or hydrophilic properties if the rough surface is not properly treated with low surface energy material or not contained with other hydrophobic functional groups on the surface or at very high surface roughness $(>4000 \mathrm{~nm})$. Increasing the Ra or RMS value on the hydrophobic treated rough surface would also increase the surface contact angle up to an optimal level [30]. RMS also has similar property like Ra. When RMS value is less than $10 \mathrm{~nm}$, the surface can show hydrophilic or hydrophobic property. MeSiOr EZ aerogel showed the surface roughness maximum (Ra) $\sim 68.9 \mathrm{~nm}$ and the root mean square (RMS) roughness $\sim 86.6 \mathrm{~nm}$, whereas the Ra and RMS values were increased partially to $\sim 95.1 \mathrm{~nm}$ and $115.2 \mathrm{~nm}$ by using MTMS under the similar conditions. The obtained results clearly showed the rough surface was created by the formation of hierarchical surface morphology. The surface roughness was enhanced further by mixing the suspensions in PMHOS. The hybrid substrate obtained by these two combinations showed the Ra and RMS values were $\sim 166 \mathrm{~nm}$ and $\sim 207.1 \mathrm{~nm}$ for PEZE and $\sim 194.7 \mathrm{~nm}$ and $244.2 \mathrm{~nm}$ for PMZE, respectively. Owing to the higher $\mathrm{Ra}$ and RMS values of the hybrid materials, the fabricated surface showed very high surface contact angle. Three dimensional (3D) (left), two


Figure $1 \mathrm{HR}$-SEM images of silica ormosil aerogels at various volume of methanol in MTES ((a) MeSiOr EX, (b) MeSiOr EY, and (c) MeSiOr EZ). (d) MeSiOr MZ from MTMS, and PMHOS/silica ormosil aerogel hybrids from MeSiOr EZ and MeSiOr MZ ((e) PEZE, and (f) PMZE). For sample notations, see Table 1. 




Figure 2 HR-TEM images of PMHOS/silica ormosil aerogel hybrid from MeSiOr E35 (PEZE) with (a) lower (5 $\mu \mathrm{m})$ and (b) higher (50 nm) resolutions. For sample notations, see Table 1.




dimensional (2D) (center) views and their line profiles (right) proved the higher surface roughness created on the spin coated substrates (Figure 3 ).

The porous structure of the material was confirmed further by $\mathrm{N}_{2}$ adsorption and desorption isotherm curves. The synthesized silica ormosil aerogels showed disordered mesoporous structures with type (IV) hysteresis loop (Figure $4(\mathrm{a}-\mathrm{c})$ ). The disordered mesostructure was also obtained by hydroxylation and condensation of PMHS with surface area, pore volume and pore diameter of $410\left(\mathrm{~m}^{2} / \mathrm{g}\right), 1.0\left(\mathrm{~cm}^{3} / \mathrm{g}\right)$, and $25.2 \mathrm{~nm}$, respectively, according to our previous study [23]. The $\mathrm{N}_{2}$ adsorption and desorption quantity was reduced by increasing the volume of methanol to the silane precursor. Similarly, the surface areas, pore volumes, and pore diameters were reduced when the volume of methanol increased. In the mean time, the void between the adsorption and desorption curves were increased due to the creation of more porous gaps between the functional silica ormosil aerogel networks (Figure 1(a-c)) [11]. Thielemann et al. explained the effect of solvent upon the changes of surface area, pore volume and pore diameter in SBA-15 mesoporous material [31]. The surface area, pore volume and pore diameter were increased at lower volume of solvent, whereas they decreased by increasing the volume of solvent. The PEZE hybrid material also showed type (IV) hysteresis loop (Figure 4d). On the other hand, a sharp $\mathrm{N}_{2}$ adsorption and desorption isotherm curve was observed. The detailed structural parameters of porous materials are listed in Table 2. The chemical compositions present in the functional silica ormosil aerogel were measured by XPS. The XPS patterns clearly showed the presence of carbon, oxygen and silicon in the ormosil aerogels with similar peak intensities (Figure 5a-d). The results indicate that there are partial changes occurred in the chemical compositions by increasing the volume of methanol. Meanwhile, the dispersibility of the material becomes rather uniform at higher volume of methanol. The intensity of the XPS peak was decreased by mixing the silica ormosil aerogels with PMHOS suspension, which indicates the uniform distribution and surface interactions of MeSiOr EZ or MeSiOr MZ with PMHOS (Figure 5e and $\mathrm{f}$ ).

The thermal stability of PMHOS, according to various silica ormosil aerogels and PMHOS/silica ormosil aerogels are shown in Figure 6. The volatilization and depolymerization of methyl group in PMHOS at $500^{\circ} \mathrm{C}-600^{\circ} \mathrm{C}$ were already discussed in our previous study (Figure 6a) [25]. At this temperature, the superhydrophobicity of PMHOS changed to superhydrophilicity due to the partial loss of hydrophobic functional groups on the material surface. On the other hand, the thermal stability of the synthesized silica ormosil aerogel was increased gradually by increasing the volume of methanol in MTES (Figure 6b-d). The gelation can occur faster at lower volume of methanol in acid/base catalyst than at higher volumes, meaning that the aggregation of methyl group capped silicon networks reduced the free movements of siloxane chains for further condensation. This might be the reason for the reduced thermal stability of the same volume of silane precursor in the silica ormosil aerogel. On the other hand, the increase in thermal stability might be due to the formation of porous structure with complete gelation of enhanced silica ormosil aerogel networks. The thermal decompositions of the silica ormosil aerogels were occurred in two stages. The initial decomposition of the materials was occurred at $\sim 210-220^{\circ} \mathrm{C}$ by the evaporation of excess water. Budunoglu et al. predicted the maximum thermal stability of the silica ormosil aerogel was $\sim 500$ $600^{\circ} \mathrm{C}$, when the concentration of methanol to MTMS $\sim 35$ mole fractions [11]. On the other hand, the present work illustrates the maximum degradations were occurred from $\sim 510^{\circ} \mathrm{C}$, to $\sim 676^{\circ} \mathrm{C}$, by increasing the volume of methanol to MTES. The enhanced stability was due to the presence of methyl capped functional group on the surface of silica ormosil aerogel networks, which maintains


Figure 4 (A) $\mathrm{N}_{2}$ adsorption and desorption isotherms and (B) pore size distribution curves of silica ormosil aerogels at various volume of methanol in MTES ((a) MeSiOr EX, (b) MeSiOr EY, and (c) MeSiOr EZ), and PMHOS/silica ormosil aerogel hybrid from MeSiOr EZ (PEZE) (d). For sample notations, see Table 1. 
Table 2 BET surface areas, pore volumes, and pore diameters of silica ormosil aerogels, PMHOS and PMHOS/ silica ormosil aerogel hybrid

\begin{tabular}{llll}
\hline Sample name & $\begin{array}{l}\text { Surface area } \\
\left(\mathbf{m}^{2} \mathbf{g}^{-1}\right)^{(\mathbf{a})}\end{array}$ & $\begin{array}{l}\text { Pore volume } \\
\left(\mathbf{c m}^{\mathbf{3}} \mathbf{g}^{-1}\right)\end{array}$ & $\begin{array}{l}\text { Pore diameter } \\
(\mathbf{n m})^{(\mathbf{b})}\end{array}$ \\
\hline MeSiOr EX & 661 & 1.74 & 34.2 \\
MeSiOr EY & 559 & 1.55 & 27.3 \\
MeSiOr EZ & 529 & 0.5 & 26.8 \\
PMHOS & 413.11 & 1 & $25.2^{[23]}$ \\
PEZE & 527 & 1.19 & 20.3 \\
\hline
\end{tabular}

Note: ${ }^{(a)}$ - BET (Brunauer-Emmett-Teller) surface area, ${ }^{(b)}$ calculated from the adsorption branch of the $\mathrm{N}_{2}$ sorption curves using BJH (Barrett-Joyner-Halenda) analysis.

the volatilization and decomposition of organic groups at higher temperatures. On the other hand, the materials were oxidized partially when the temperature increased to over $500^{\circ} \mathrm{C}$, which may also change the surface property from superhydrophobic to superhydrophilic. The maximum degradation of the materials was due to the decomposition of capped methyl group on the surface of silica ormosil aerogel networks. Thermal stability of phenyl substituted silica ormosil was reported as high [23]. The addition of $\mathrm{MeSiOr}$ aerogel to the PMHOS $\left(206^{\circ} \mathrm{C}\right.$ initial; $508^{\circ} \mathrm{C}$, maximum decomposition) results to the enhancement of thermal stability $\left(218^{\circ} \mathrm{C}\right.$ initial; $545^{\circ} \mathrm{C}$, maximum) due to the deposition of additional hydrophobic methyl groups by silica ormosil aerogels on the siloxane networks of PMHOS (Figure 6e). The residual mass was also increased after the decomposition of PEZE, which confirmed the increased thermal stability of PMHOS by





MeSiOr aerogel. Similar trends of decompositions were observed in $\mathrm{MeSiOr} \mathrm{MZ}\left(216^{\circ} \mathrm{C}\right.$ initial; $541^{\circ} \mathrm{C}$, maximum) as well as PMZE hybrid $\left(210^{\circ} \mathrm{C}\right.$, initial; $527^{\circ} \mathrm{C}$, maximum) (Figure $6 \mathrm{f}$ and $\mathrm{g}$ ).

The silica ormosil aerogel redispersed in methanol showed partially enhanced transparency on the spin coated substrate (Figure 7a-c). Budunoglu et al. discussed the transparency of silica ormosil aerogel obtained from MTMS under various curing temperatures [11]. At room temperature, the spin coated substrate showed $\sim 65-75 \%$ in the visible region. On the other hand, the transparency of the coated substrate was enhanced dramatically by increasing the thermal annealing temperature from room temperature to $500^{\circ} \mathrm{C}$ ( $~ 90 \%$ transparency) due to reduced back reflections [11]. Similar transparent substrate was fabricated by spin coating on a glass substrate followed the evaporation of solvent at room temperature using $\mathrm{MeSiOr}$ suspensions (Figure 7a-c). Similarly, the spin coated superhydrophobic PMHOS glass substrate showed transparent ( $85 \%)$ surface property at room temperature when dispersing in methanol (Figure 8). The transparency of the substrate was reduced partially by the addition of MeSiOr EZ suspension to the PMHOS suspension. Increasing the weight percentages of MeSiOr EZ suspension to the PMHOS suspension further reduced the transparency due to formation of hierarchical surface morphology by aggregation of PMHOS and MeSiOr EZ (Figure 8). Meanwhile, the spin coated substrate maintained reasonable transparency on the substrate. The fabrication of transparent substrates was confirmed from the optical images and UV-visible spectra (Figure 8). 




Figure 7 Optical images of silica ormosil aerogels at various volume of methanol in MTES ((a) MeSiOr EX, (b) MeSiOr EY, and (c) MeSiOr EZ) and their contact angle values (d-f). For sample notations, see Table 1.

Wettability of the substrate is an important phenomenon for using the material for self-cleaning coatings. PMHOS showed superhydrophobic property when dispersing into methanol with contact angle (CA) of $174.2^{\circ} \pm 1.0^{\circ}$ (Figure 9a) [23]. Meanwhile, the silica ormosil aerogel suspension obtained from MTES or MTMS showed almost complete superhydrophobicity $\left(\sim 178.0^{\circ} \pm 1.0^{\circ}\right)$ (Figure $7 \mathrm{~d}$-f). The addition of small amounts of $\mathrm{MeSiOr}$ EZ suspension or MeSiOr MZ suspension to the PMHOS suspension showed the increased contact angle on the spin coated substrate (Figure $9 \mathrm{~b}$ and c). This is due to the aggregation of superhydrophobic silica ormosil aerogel on the PMHOS surface by hydrophobic effect, which enhanced the surface roughness of the hierarchical micronanoparticles. The higher surface roughness would increase the surface contact angle more preferably. HRTEM and AFM images clearly showed the hierarchical surface roughness of the hybrid material (Figures 2 and 3). Increasing the weight percentages of $\mathrm{MeSiOr} \mathrm{EZ}$ suspension to the PMHOS suspension would also increase the surface

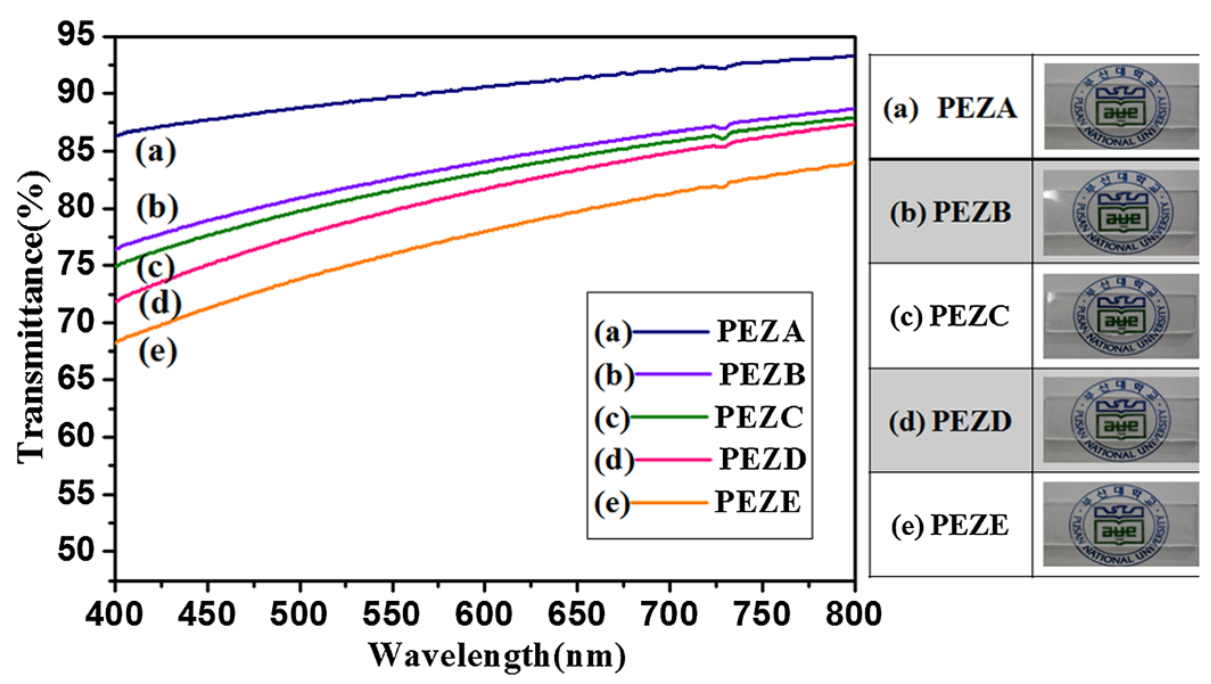

Figure $8 \%$ Transmittance (left) with the optical images (right) of PMHOS/silica ormosil aerogel hybrids prepared with various weight percentages of MeSiOr EZ (a (0 g), b (0.02 g), c (0.04 g), d (0.08 g), and e (0.1 g)) with PMHOS. 




Figure 9 Static contact angles of PMHOS/silica ormosil aerogel hybrid substrates prepared at various weight percentages of MeSiOr EZ (a-e) and MeSiOr MZ (f-j) with PMHOS. For sample notations, see Table 1.

contact angle based on the mechanism of enhanced surface hydrophobicity and surface roughness (Figure 9a-e). Our previous study showed partially reduced surface contact angle (maintained the superhydrophobicity with CA over $173.5^{\circ} \pm 4.0^{\circ}$ ) of the similar system when using mixture of ethanol and methanol solvents for PMHOS and silica ormosil aerogel prepared from PTES [23]. In another case, we also found the decrease of surface contact angle from superhydrophobic to stable hydrophobic by the addition of hydrophilic silica nanoparticles $\left(146.13^{\circ} \pm 4.0^{\circ}\right)$ suspension or amino functionalized silica ormosils suspensions $\left(136.76^{\circ} \pm 3.0^{\circ}\right.$, and $\left.134.0^{\circ} \pm 3.0^{\circ}\right)$ ) to the PMHOS suspension in ethanol/N,N dimethylacetamide (DMAc) solvents. The present study showed the enhanced surface contact angle with almost complete superhydrophobicity and reasonable transparency using similar type of cosolvent (methanol) for PMHOS suspension and for silica ormosil aerogel suspension. Similar surface wettability also obtained by the addition of various weight percentages of MeSiOr MZ suspension to PMHOS suspension (Figure 9f-j).

\section{Conclusions}

In this work, we successfully fabricated transparent substrate with superhydrophobicity on a glass substrate using various ratios and types of silica ormosil aerogels and their hybrid materials. The surface of the materials showed the formation of hierarchical surface morphology with high roughness created on the surface by the introduction of silica ormosil aerogel to the polymethylhydroxysiloxane. The synthesized silica ormosil aerogel and hybrid materials showed disordered meso structures. However, the surface areas, pore volumes and pore diameters of the silica ormosil aerogel were decreased by increasing the volume of methanol. Similarly, the transparency of the spin coated substrates also decreased partially by aggregation but with maintaining reasonable transparency. On the other hand, the thermal stability was increased by increasing the volume percentages of methanol to the silane precursors. The addition of silica ormosil aerogel to the PMHOS showed the enhanced the surface properties as well as the thermal stability of the hybrid material. The obtained results exhibit the important contribution of silica ormosil aerogels to the PMHOS for the enhancement of various properties of the hybrid material in a cosolvent by comparing with the materials obtained from ethanol/methanol/water or ethanol/DMAc/water solvents. On the other hand, the stability of the hybrid suspensions is not so good over a period of time under rest. The main reason is due to the deposition of the hybrid particles in the solvents in a few hours. Meanwhile, superhydrophobic surface can be fabricated easily at any time by simple shaking of the suspension for a few seconds followed by coating on a glass substrate. 


\section{Competing interests}

The authors declare that they have no competing interests.

\section{Authors' contribution}

SN carried out the synthesis of superhydrophobic PMHOS, writing and formatting of the full manuscript according to the journal. JJP carried out the synthesis of silica ormosil aerogels and hybrid materials with the help of $\mathrm{SN}$. Both authors thoroughly characterized the material using several characterization techniques. SSP and CSH were participated in this experiment and carefully revised the manuscript. All authors read and approved the final manuscript.

\section{Acknowledgements}

This study was supported by the National Research Foundation of Korea (NRF) Grant funded by The Ministry of Science, ICT \& Future Planning, Korea (Pioneer Research Center Program (2010-0019308/2010-0019482), NRF-RFBR Joint Research Program (No. 2013K2A1A7076267), and Brain Korea 21 Plus Program (21A2013800002)).

Received: 3 September 2014 Accepted: 15 September 2014

Published online: 02 December 2014

\section{References}

1. S Nagappan, SS Park, CS Ha, J. Nanosci. Nanotechnol. 14, 1441 (2014)

2. SS Latthe, H Imai, V Ganesan, C Kappenstein, A Venkateswara Rao, J. Sol-Gel Sci. Technol. 53, 208 (2010)

3. QF Xu, JN Wang, KD Sanderson, ACS Nano 4, 2201 (2010)

4. CH Su, J Li, HB Geng, QJ Wang, QM Chen, Appl. Surf. Sci. 253, 2633 (2006)

5. X Deng, L Mammen, Y Zhao, P Lellig, K Müllen, C Li, HJ Butt, D Vollmer, Adv. Mater. 23, 2962 (2011)

6. S Nagappan, MC Choi, G Sung, SS Park, MS Moorthy, SW Chu, WK Lee, CS Ha, Macromol. Res. 21, 669 (2013)

7. S Nagappan, JJ Park, SS Park, SH Hong, YS Jeong, WK Lee, CS Ha, Compos. Interfaces 20, 33 (2013)

8. JA Howarter, JP Youngblood, Adv. Mater. 19, 3838 (2007)

9. NT Panagiotopoulos, EK Diamanti, LE Koutsokeras, M Baikousi, E Kordatos, TE Matikas, D Gournis, P Patsalas, ACS Nano 6, 10475 (2012)

10. J Yang, ZZ Zhang, XH Men, XH Xu, Appl. Surf. Sci. 255, 9244 (2009)

11. H Budunoglu, A Yildirim, MO Guler, M Bayindir, ACS Appl. Mater. Interfaces 3, 539 (2011)

12. Y Rahmawan, L Xu, S Yang, J. Mater. Chem. A 1, 2955 (2013)

13. L Xu, RG Karunakaran, J Guo, S Yang, ACS Appl. Mater. Interfaces 4, 1118 (2012)

14. SA Mahadik, DB Mahadik, MS Kavale, VG Parale, PB Wagh, HC Barshilia, SC Gupta, ND Hegde, A Venkateswara Rao, J. Sol-Gel Sci. Technol. 63, $580(2012)$

15. HS Hwang, NH Kim, SG Lee, DY Lee, K Cho, I Park, ACS Appl. Mater. Interfaces 3, 2179 (2011)

16. A Nakajima, A Fujishima, K Hashimoto, T Watanabe, Adv. Mater. 11, 1365 (1999)

17. A Nakajima, K Hashimoto, T Watanabe, Langmuir 16, 7044 (2000)

18. LG Xu, JH He, Langmuir 28, 7512 (2012)

19. JB Lin, HL Chen, T Fei, C Liu, JL Zhang, Appl. Surf. Sci. 273, 776 (2013)

20. Y Lai, Y Tang, J Gong, D Gong, L Chi, C Lin, Z Chen, J. Mater. Chem. $22,7420(2012)$

21. BH Kim, DH Lee, JY Kim, DO Shin, HY Jeong, S Hong, JM Yun, CM Koo, H Lee, SO Kim, Adv. Mater. 23, 5618 (2011)

22. D Zhong, Q Yang, L Guo, S Dou, K Liu, L Jiang, Nanoscale 5, 5758 (2013)

23. S Nagappan, JJ Park, SS Park, WK Lee, CS Ha, J. Mater. Chem. A 1, 6761 (2013)

24. S Nagappan, AR Sung, CS Ha, J. Biobased Mater. Bioenergy 8, 175 (2014)

25. S Nagappan, SS Park, CS Ha, Macromol. Res. 22, 843 (2014)

26. S Nagappan, JH Park, AR Sung, CS Ha, Compos. Interfaces 21, 597 (2014)
27. DJ Yang, JP Li, Y Xu, D Wu, YH Sun, HY Zhu, F Deng, Microporous Mesoporous Mater. 95, 180 (2006)

28. M Giordano, A ladonisi, Eur. J. Org. Chem. 2013, 125 (2013)

29. SJ Lee, M Goedert, MT Matyska, EM Ghandehari, M Vijay, JJ Pesek, J. Micromech. Microeng. 18, 025026 (2008)

30. KL Cho, II Liaw, AHF Wu, RN Lamb, J. Phys. Chem. C 114, 11228 (2010)

31. JP Thielemann, F Girgsdies, R Schlögl, C Hess, Beilstein J. Nanotechnol. 2, 110 (2011)

doi:10.1186/s40580-014-0030-6

Cite this article as: Nagappan et al:: Preparation of superhydrophobic and transparent micro-nano hybrid coatings from polymethylhydroxysiloxane and silica ormosil aerogels. Nano Convergence 2014 1:30.

\section{Submit your manuscript to a SpringerOpen ${ }^{\circ}$ journal and benefit from:}

- Convenient online submission

- Rigorous peer review

- Immediate publication on acceptance

- Open access: articles freely available online

- High visibility within the field

- Retaining the copyright to your article

Submit your next manuscript at $>$ springeropen.com 